\title{
Factors contributing to the outcome of stocking programmes in Cuban reservoirs
}

\author{
R. QUIROS \\ Agronomy Faculty, Buenos Aires University, Buenos Aires, Argentina
}

A. MARI

Miami, Florida, USA

\begin{abstract}
In less-developed countries, fisheries enhancement using stocking is a common practice to manage reservoirs for biomass production. In many cases, there appears to be little control over whether the stocking activity is appropriate or necessary. Cuban reservoir fisheries have been usually managed to maximize fish biomass. Blue tilapia have been introduced and supplemented in reservoirs, and Chinese carp are introduced and maintained in reservoirs throughout the entire island. Supplemental stocking with introduced fish species is a usual practice to manage large and medium-sized reservoirs. Small and very small reservoirs have been managed as semi-intensively enhanced fisheries with carp and tilapia stocking. The main purposes of the present paper are to study the factors contributing to the outcome of stocking programmes in reservoirs and to test the hypotheses that supplementary stocking for selfsustained fish populations usually cannot contribute to increase fish yield. Yield and stocking data by groups of fish species were available for Cuban reservoirs. Total fish yield was only slightly related to total fish stocking density for the complete set of reservoirs. However, this result was mainly because of the relationship between total yield and cyprinid stocking for semi-intensively-used reservoirs. Tilapia yield was not significantly related to tilapia stocking for both extensively and semi-intensively-used reservoirs. However, yield and stocking for cyprinids were highly related for both reservoir subsets. Therefore, cyprinid stocking was effective in certain reservoirs, but tilapia stocking was not effective in any reservoir. Moreover, tilapia stocking was a superfluous activity for reservoirs where tilapia have an adequate natural reproduction cycle.
\end{abstract}

KEYWORDS: fish yield, self-sustained fish populations, stocking rate, tropical reservoirs.

\section{Introduction}

In the continuum from capture to culture, fisheries stocking is the most widespread tool used for management (Welcomme \& Bartley 1998). In less developed countries, fisheries enhancement using stocking is a common practice to manage reservoirs for biomass production. However, in many cases, there appears to be little control over whether the stocking activity is appropriate or necessary (Cowx 1999). In Latin America and the Caribbean,

Correspondence: Rolando Quiros, Agronomy Faculty, Buenos Aires University, Av. San Martin 4453, 1417 CF, Buenos Aires, Argentina (e-mail: quiros@ifeva.edu.ar). 
reservoir fisheries have usually been exploited on a trial-and-error basis (Quiros 1994); reservoirs have been stocked in many areas of the region for many years, but an assessment of stocking effectiveness has never been conducted (Quiros 1998). Cuban reservoirs constitute an exception (Fonticiella, Arboleya \& Diaz Perez 1995).

Cuban reservoir fisheries have usually been managed to maximize fish biomass (Mari 1992). Supplemental stocking with introduced fish species is a common practice in large and mediumsized reservoirs in Cuba. Small and very small reservoirs are managed by semi-intensive stocking with Chinese carp and tilapia. Stocking began in 1973 with tilapia, Oreochromis aureus Steindachner. The fish were mainly stocked in large reservoirs at high densities and tilapia fisheries have developed since 1977 in most reservoirs larger than 100 ha (Mari 1992; Fonticiella et al. 1995). The stocking of Chinese carp was mainly restricted to small and very small reservoirs, although some medium-sized and large reservoirs were also stocked (Fonticiella et al. 1995). High stocking densities were also evident in individual reservoirs for both tilapia and cyprinids in 1992 and 1993. Among the stocked fish, only tilapia in large, medium-sized and many of the small reservoirs have undergone natural recruitment to fishable populations. Chinese carp are usually bred in public hatcheries. In the last few years, some medium-sized reservoirs which were used for extensive tilapia fisheries were moved to semiintensive cyprinid culture. For the country as a whole, an increased number of provinces have reported stocking in reservoirs as a successful management technique. However, numbers or weight of fish stocked are inadequate measures of management success. Stocking rate alone may be a poor indicator of the survival of stocked material or of its contribution to the catch (Welcomme 1998).

The primary aims of this present paper are to examine the factors contributing to the outcome of stocking programmes in Cuban reservoirs and to test the hypothesis that supplementary stocking of self-sustained fish populations does not lead to increased fish yield. The secondary aims are: to study how maintenance stocking for non-reproducing fish species is reflected in fish yield; to analyse results from time-series analyses between yield and stocking by species for selected reservoirs; to explore management implications to enhance reservoir fisheries using stocking; and to identify the general circumstances where stocking is wasteful.

\section{Materials and methods}

A database was constructed to examine the effects of fish stocking on fish yield. For Cuban reservoirs, yield and stocking data by groups of fish species were available. The database included large and medium-sized reservoirs, and small and very small reservoirs (Fonticiella et al. 1995; L. Remedios and C. Cabezas, unpublished data; for the total data set, see Quiros 1998). All water bodies are used for culture-based fisheries or aquaculture (Table 1). For most of the large and medium-sized reservoirs, climatic and morphoedaphic effects on fish yield have been previously studied (A. Mari and R. Quiros, unpublished data).

For extensively-used reservoirs $(n=57)$, the data employed for between-reservoir comparisons were current yield (year y) compared with the stocking density 3 years previously (year $y-3$ ). For this time-lag, the relationship between yields and stocking rates (year y -3 ) shows the best correlation. Moreover, the age of most fish at capture was between 2 and 
Table 1 Fisheries and stocking characteristics for extensively (grade $1, n=57$ ) and semi-intensively (grade 2, $n=29$ ) used Cuban reservoirs.

\begin{tabular}{|c|c|c|}
\hline Variable & Grade 1 & Grade 2 \\
\hline Surface area $(\mathrm{A}, \mathrm{ha})$ & $1103(10-7945)$ & $115(5-1063)$ \\
\hline Total fish yield $\left(\mathrm{Y}, \mathrm{kg} \mathrm{ha}^{-1}\right.$ year $\left.^{-1}\right)$ & $212(19-902)$ & $687(78-2032)$ \\
\hline Tilapia yield (YTi, $\mathrm{kg} \mathrm{ha}^{-1}$ year $\left.^{-1}\right)$ & $210(27-845)$ & $184(14-853)$ \\
\hline Chinese carp yield (YCy, $\mathrm{kg} \mathrm{ha}^{-1}$ year $^{-1}$ ) & $13.4(0-98.3)$ & $460.4(0.2-1919)$ \\
\hline Fishing effort per unit area (man days $\mathrm{ha}^{-1}$ year $^{-1}$ ) & $2.9(0.5-9.4)$ & $11.9(2.3-43.2)$ \\
\hline Stocking rate (SDN, fish $\mathrm{ha}^{-1} \mathrm{year}^{-1}$ ) & $865(36-11126)$ & $3713(559-11814)$ \\
\hline Stocking rate (SDW, fish $\mathrm{ha}^{-1}$ year $^{-1}$ ) & $5.7(0.5-33.0)$ & $23.8(2.6-96.3)$ \\
\hline Mean weight at stocking $(\mathrm{W}, \mathrm{g})$ & 6.6 & 6.4 \\
\hline Tilapia stocking (SDWTi, fish ha ${ }^{-1}$ year $^{-1}$ ) & $4.1(0-32.3)$ & $5.5(0-16.8)$ \\
\hline Carp stocking (SDWCy, fish $\mathrm{ha}^{-1}$ year $^{-1}$ ) & $1.7(0-15.3)$ & $18.3(0-91.8)$ \\
\hline
\end{tabular}

3 years. For semi-intensive reservoirs $(n=29)$, most fish were captured one year after stocking (year y-1) (Fonticiella et al. 1995; L. Remedios and C. Cabezas, unpublished data). Therefore, for this kind of reservoir, relationships were derived from captures in year y and stocking densities in year $y-1$. The ratio of cyprinid biomass to total fish biomass both for stocking and yield was used to study any effects of cyprinid stocking on total yield.

The data were analysed by linear correlation, partial correlation, and simple and multiple regression on the total data and on several data subsets (Weisberg 1980). Stepwise multiple regression analysis was applied to the data using variables related to fisheries and stocking. The Number Cruncher Statistical System (NCSS; Hintze 1988) was used. Time-series relations between yields and stockings for individual reservoirs were studied using lag-correlation techniques (Davis 1986). To account for the intensity of use of fish production for each aquatic environment, a dummy variable denominated grade of intensification was defined as 1 and 2 for extensively (no fertilization or feeding) and semi-intensively (just fertilization) used reservoirs, respectively. Original information given by the present authors was used to adjudicate grade value. To stabilize the variance, all the variables except grade and fish biomass ratios were log-transformed. The latter were arc-sine transformed because these were proportions (Draper \& Smith 1981). The efficiency of stocking was considered in terms of yield per unit stocked (Welcomme \& Bartley 1998).

\section{Results}

The fish yields and stocking densities for tilapia in 49 reservoirs are shown in Figure 1a for the period from 1973 to 1993. After the initial stocking, stocking densities were held constant, but yields have increased. Stocking strategies for tilapia have changed markedly since 1990. An increase in tilapia stocking densities in both weight and numbers was noticeable. During the period from 1990 to 1993, hatchery rearing patterns have shifted toward producing a bigger number of smaller fish (Diaz Perez, personal communication). The stocking of cyprinids, i.e. Hypophthalmicthys molitrix (Valenciennes, 1884), Hypophthalmicthys nobilis (Richardson, 1845), Cyprinus carpio L. and Ctenopharyngodon idella (Valenciennes, 1884), also began in the early 1970s, with a noticeable increase after 1984 (Fig. 1b). 

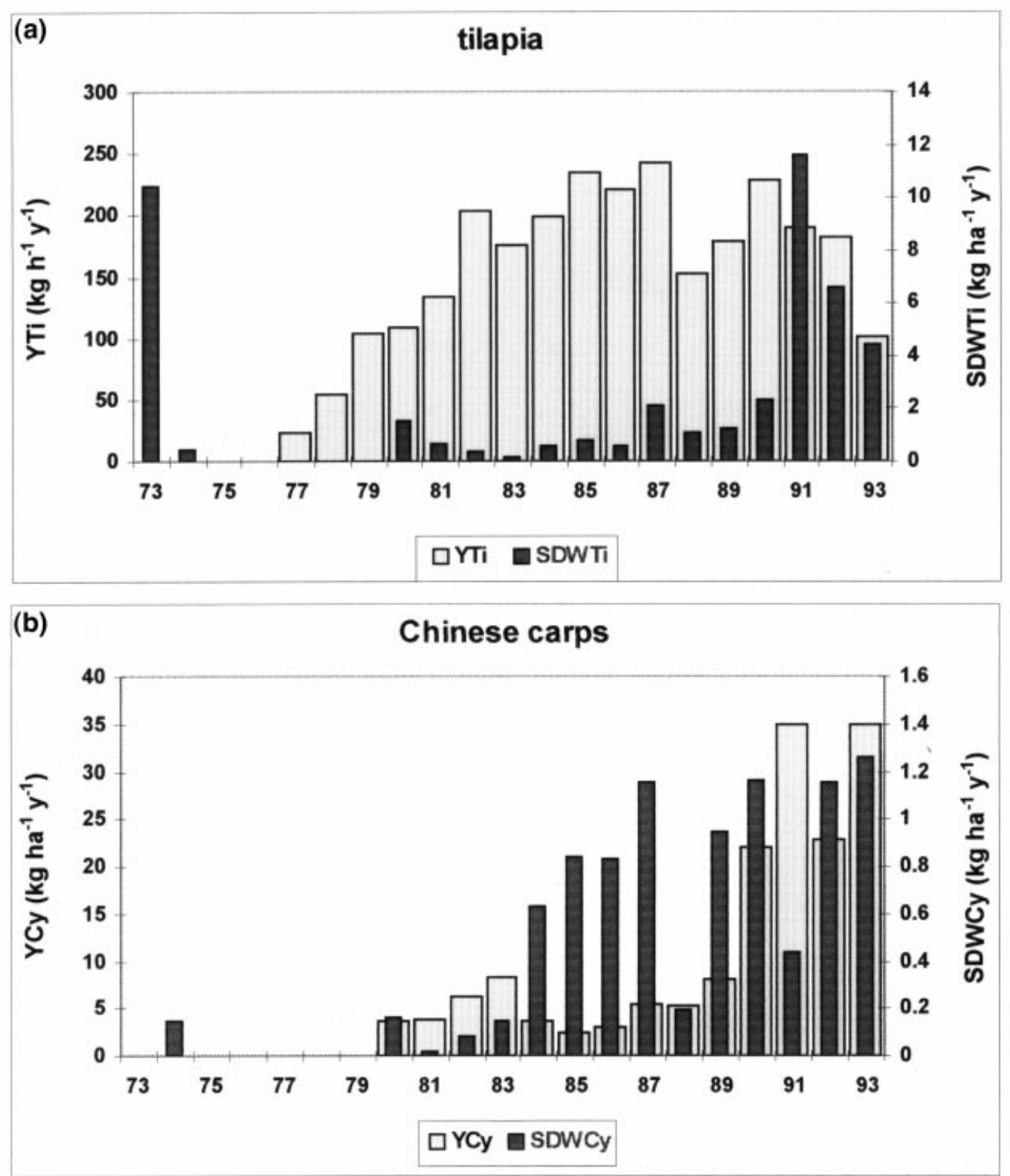

Figure 1. (a) Tilapia yield (YTi, $\mathrm{kg} \mathrm{ha}^{-1}$ year $^{-1}$ ) and stocking density in weight (SDWTi, $\mathrm{kg} \mathrm{ha}^{-1} \mathrm{year}^{-1}$ ), and (b) Chinese carp yield (YCy, $\mathrm{kg} \mathrm{ha}^{-1}$ year $^{-1}$ ) and stocking density in weight (SDWCy, $\mathrm{kg} \mathrm{ha}^{-1}$ year ${ }^{-1}$ ) for 49 Cuban extensively used reservoirs.

Total fish yield was only slightly related to total fish stocking rate for the complete data set (Figure 2), although this was mainly a result of the relationship between total yield and cyprinid stocking for semi-intensively used reservoirs (Table 2). As expected, total fish yield and fishing effort per unit area were highly related $(P<0.01)$ for total Cuban reservoirs (Table $2, n=67)$, and for both extensively and semi-intensively used reservoirs $(P<0.01$, 


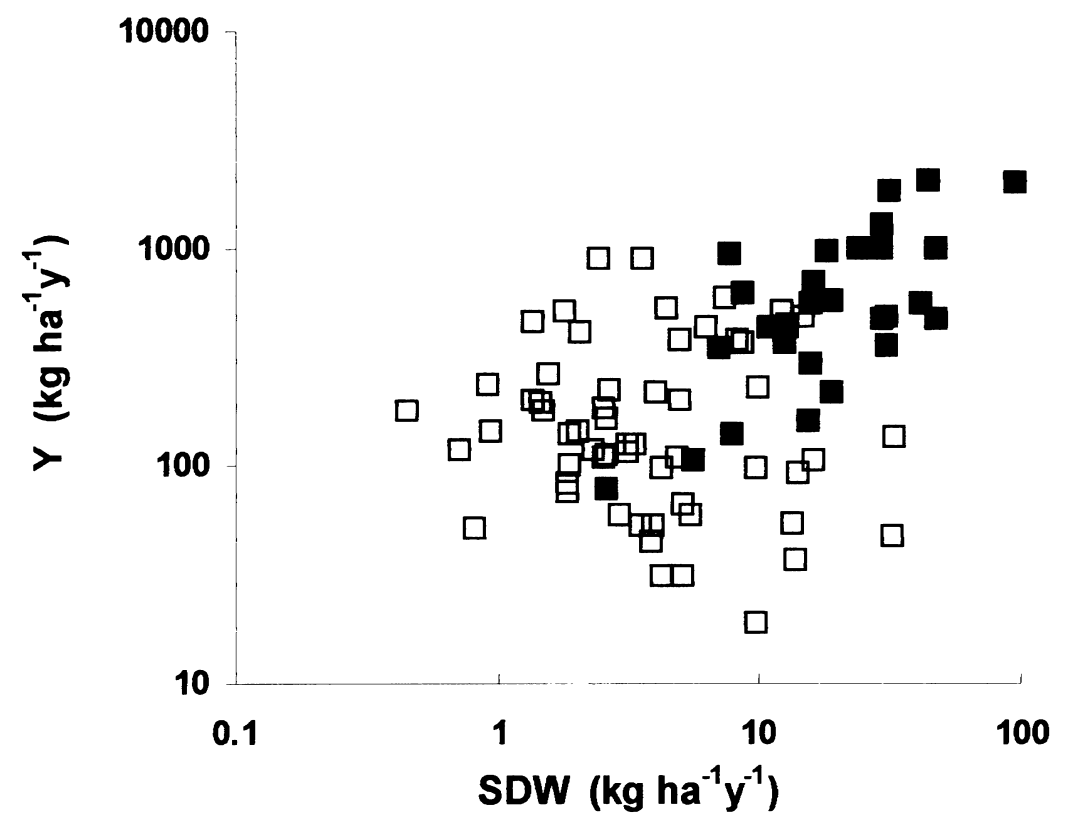

Figure 2 Relationship between fish yield $\left(\mathrm{Y}, \mathrm{kg} \mathrm{ha}^{-1} \mathrm{year}^{-1}\right)$ and stocking density in weight (SDW, $\mathrm{kg} \mathrm{ha}^{-1} \mathrm{year}^{-1}$ ) for 86 Cuban reservoirs: $(\square)$ extensively used reservoirs; and (ם) semi-intensively used reservoirs.

Tables 3 \& 4) (Quiros 1998). Both variables were also strongly related when surface area was held constant in partial correlation analysis $(r=0.88, n=67)$. Similar results were obtained for large, small and very small reservoirs situated in South America (Quiros 1994).

\section{Stocking effectiveness for extensively used reservoirs}

Total fish yield and total fish stocking rate were not related for extensively used reservoirs (grade 1) (Table 3, Fig. 2). Moreover, total yield was also not related to surface area or to fish species stocking rates (Table 3$)(P>0.05)$.

Tilapia yields, as well as total fish yields, were not significantly $(P>0.05)$ related to tilapia stockings for extensively used reservoirs (Fig. 3). On the other hand, yields and stockings for cyprinids were strongly related (Fig. 4, Table 3 ).

Table 2 Correlation matrix for all Cuban reservoirs $(n=86)$. Variables as defined in Table 1.*

\begin{tabular}{lcccccc}
\hline & A & SDW & SDWTi & SDWCy & Effort & \#grade \\
\hline Y & -0.49 & 0.44 & -0.05 & 0.60 & $\mathbf{0 . 8 7}$ & 0.57 \\
YTi & 0.17 & -0.20 & $-\mathbf{0 . 1 4}$ & -0.16 & 0.28 & -0.17 \\
YCy & -0.78 & 0.73 & 0.29 & $\mathbf{0 . 8 7}$ & 0.78 & 0.65 \\
SDW & -0.74 & 1 & 0.54 & 0.83 & 0.63 & 0.66 \\
SDWTi & -0.15 & 0.54 & 1 & 0.12 & 0.17 & 0.15 \\
SDWCy & -0.76 & 0.83 & 0.12 & 1 & 0.76 & 0.73 \\
\hline
\end{tabular}

$* r=0.18 ; P=0.05 ; r=0.25, P=0.01$.

(C) 1999 Blackwell Science Ltd, Fisheries Management and Ecology 1999, 5, 241-254 
Table 3 Correlation matrix for extensively $(n=57)$ used Cuban reservoirs. Variables as defined in Table $1 . *$

\begin{tabular}{lcccrr}
\hline & A & SDW & SDWTi & SDWCy & Effort \\
\hline Y & -0.07 & -0.12 & -0.22 & 0.05 & $\mathbf{0 . 8 2}$ \\
YTi & -0.24 & -0.04 & $-\mathbf{0 . 1 1}$ & 0.12 & $\mathbf{0 . 7 7}$ \\
YCy & -0.47 & 0.27 & -0.01 & $\mathbf{0 . 6 3}$ & 0.58 \\
SDW & -0.53 & 1 & 0.77 & 0.57 & 0.11 \\
SDWTi & -0.20 & 0.77 & 1 & 0.03 & -0.03 \\
SDWCy & -0.48 & 0.57 & 0.03 & 1 & 0.29 \\
\hline
\end{tabular}

$* r=0.22, P=0.05 ; r=0.30, P=0.01$.

Cyprinid yield was inversely related to surface area (Table 3) $(P>0.01)$, but this relationship was not highly significant $(P>0.01)$ when cyprinid stocking density was held constant in partial correlation analysis $(r=-0.24, n=41)$.

The efficiency of stocking (yield per unit stocked) for tilapia was not significantly related to surface area. However, this efficiency for cyprinids was highly related to surface area $(r=0.65$, $n=40$ ). This latter effect may be because of missing data on stocking (D. W. Fonticiella, personal communication).

\section{Stocking effectiveness for semi-intensively used reservoirs}

Total fish yield and total stocking density were highly related for semi-intensively used reservoirs (grade 2). Also, total fish yield was related to cyprinid stocking rate (Table 4). It should be stressed that the increased cyprinid stocking rate was only reflected in total yield for semi-intensively used reservoirs, whilst on the other hand, total fish yields and tilapia stockings were not related at all for Cuban reservoirs (Tables $3 \& 4$, Fig. 2).

Like total yields, tilapia yields were not significantly related to tilapia stockings for semiintensively used reservoirs (Table 3, Fig. 3). On the other hand, yields and stockings for cyprinids were highly related for semi-intensively used reservoirs (Table 3, Fig. 4).

For both extensively and semi-intensively used reservoirs, these results may indicate that the stocking of usually non-reproducing cyprinids has contributed to total yield, whereas tilapia stocking was misleading after self-sustained tilapia populations developed.

The efficiency of stocking for cyprinids was not significantly related to surface area.

Table 4 Correlation matrix for semi-intensively $(n=29)$ used Cuban reservoirs. Variables as defined in Table 1.*

\begin{tabular}{lrrrrr}
\hline & A & SDW & SDWTi & SDWCy & Effort \\
\hline Y & -0.36 & 0.69 & -0.08 & $\mathbf{0 . 7 6}$ & $\mathbf{0 . 8 6}$ \\
YTi & 0.45 & -0.27 & $-\mathbf{0 . 0 4}$ & -0.21 & 0.11 \\
YCy & -0.73 & 0.78 & -0.07 & $\mathbf{0 . 9 2}$ & 0.73 \\
SDW & -0.52 & 1 & 0.33 & 0.91 & 0.75 \\
SDWTi & 0.13 & 0.33 & 1 & 0.01 & -0.19 \\
SDWCy & -0.58 & 0.91 & 0.01 & 1 & 0.80 \\
\hline
\end{tabular}

$* r=0.31, P=0.05 ; r=0.43, P=0.01$. 


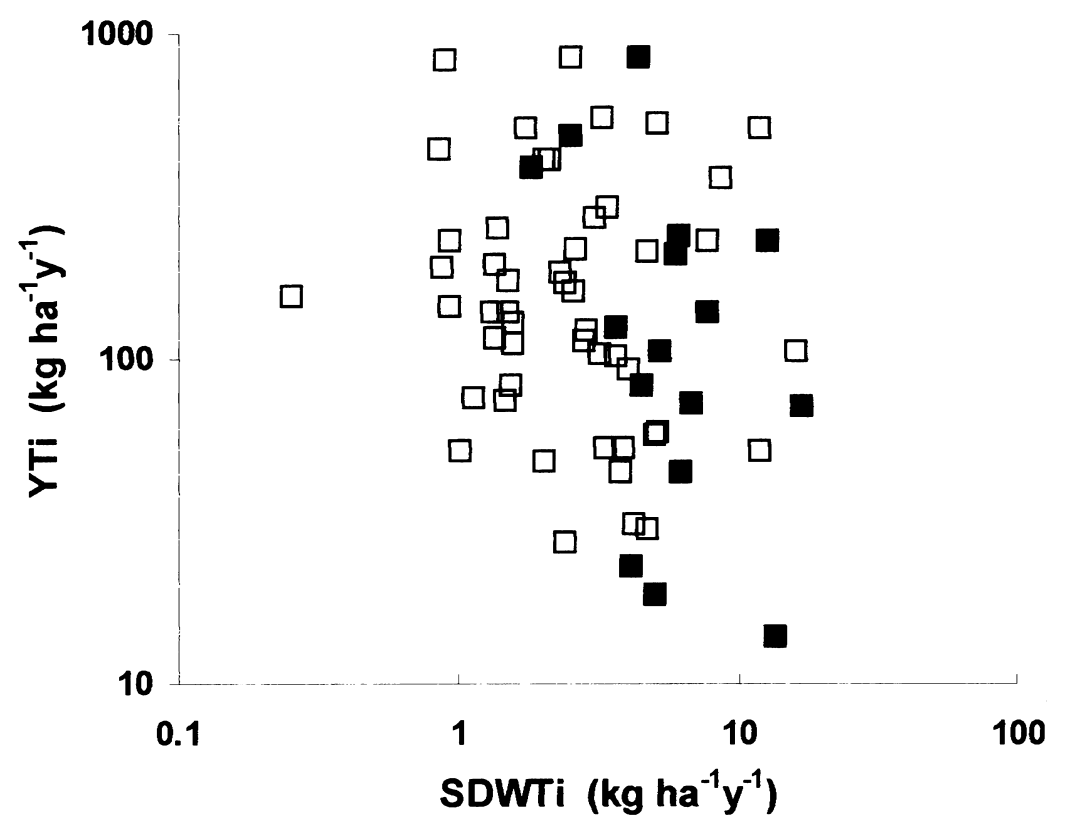

Figure 3 Relationship between tilapia yield $\left(\mathrm{YTi}, \mathrm{kg} \mathrm{ha}^{-1} \mathrm{year}^{-1}\right.$ ) and stocking density in weight (SDWTi, $\mathrm{kg}$ ha $^{-1}$ year $^{-1}$ ) for 86 Cuban reservoirs: $(\square)$ extensively used reservoirs; and (ם), semi-intensively used reservoirs.

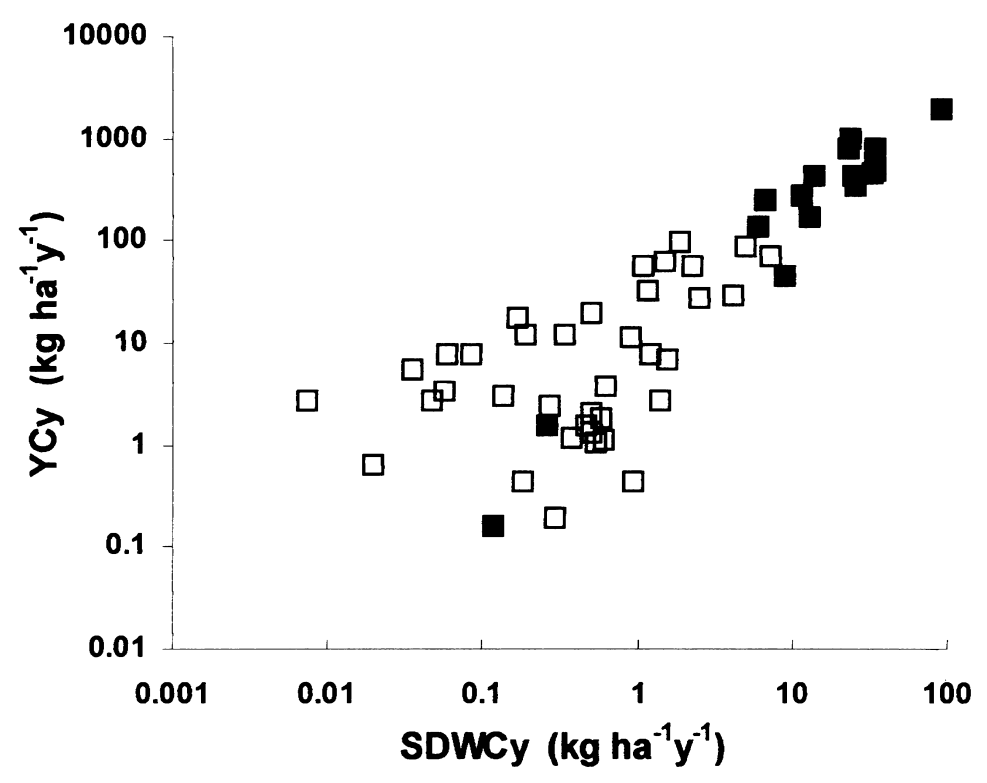

Figure 4 Relationship between cyprinid yield (YCy, $\mathrm{kg} \mathrm{ha}^{-1}$ year $^{-1}$ ) and stocking density in weight (SDWCy, $\mathrm{kg}$ ha $^{-1}$ year $^{-1}$ ) for 86 Cuban reservoirs: $(\square)$ extensively used reservoirs; and (ロ) semi-intensively used reservoirs.

(C) 1999 Blackwell Science Ltd, Fisheries Management and Ecology 1999, 5, 241-254 
Moreover, for tilapia, the efficiency was lightly related to surface area $(r=0.45, n=16)$. However, for very small reservoirs, some missing tilapia stockings data is suspected (D. W. Fonticiella, personal communication).

\section{Cyprinid stocking}

No direct relationship between the cyprinid to total biomass ratio of landings and total fish yield for extensively used reservoirs was found (Fig. 5). However, the cyprinid to total biomass ratio at stocking improved total fish yield in semi-intensively used reservoirs (Fig. 6). It is also evident for both types of reservoirs that some stocked cyprinids were not fished, but a clear threshold existed between extensively and semi-intensively used reservoirs (Fig. 7). Therefore, the impact of stocking cyprinids in the expectation of increasing yields in the extensively used reservoirs is not clear from the results obtained for Cuban reservoirs. However, some of the cyprinid stocking has not been reflected in catches yet.

\section{Time-series analyses}

The outputs from the reservoir comparisons are 'mean effect results' and many exceptions for individual reservoirs can be expected. However, similar results were obtained from time-series lag-correlation analyses for 49 extensively used reservoirs (Fig. 9). Cyprinid yield was significantly related to cyprinid stocking rates in previous years, although the relationship for 0-

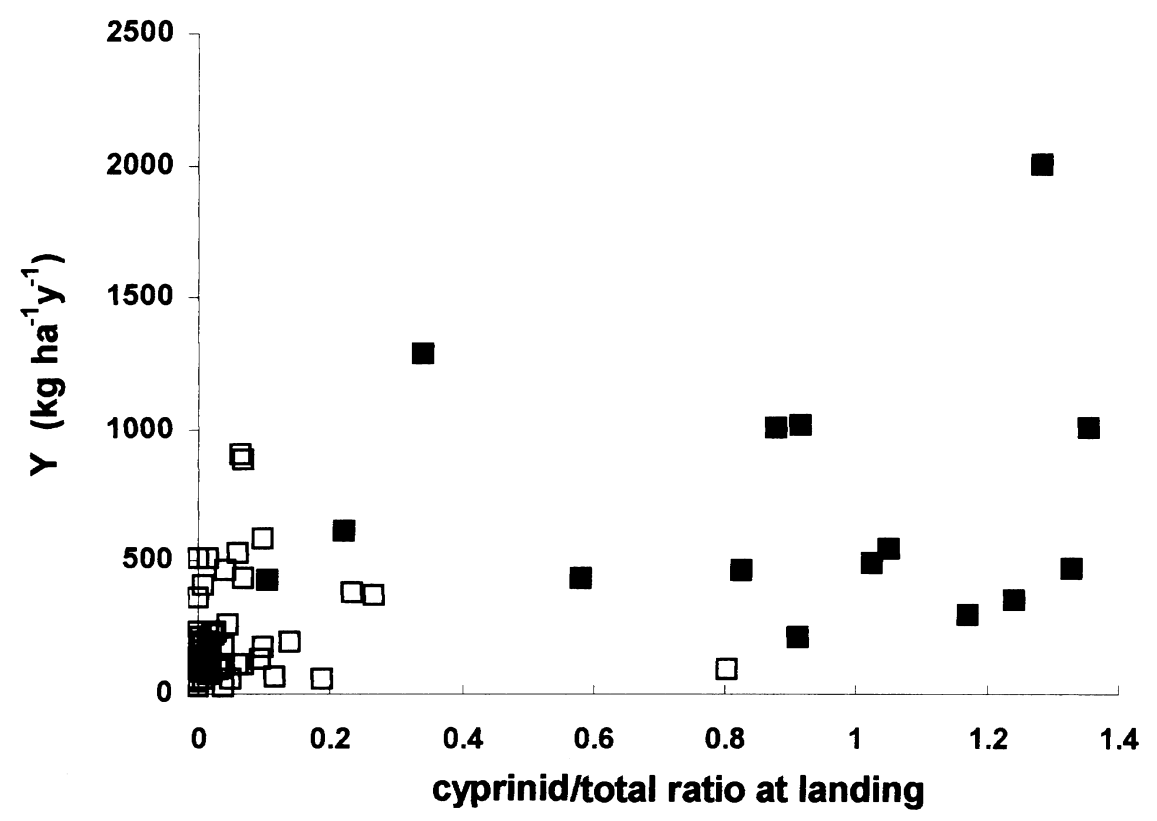

Figure 5 Relationship between total yield ( $\mathrm{Y}, \mathrm{kg} \mathrm{ha}^{-1} \mathrm{year}^{-1}$ ) and cyprinid to total fish biomass ratio at landing (arcsine transformed) for 86 Cuban reservoirs: $(\square)$ extensively used reservoirs; and ( $\square$ ) semi-intensively used reservoirs. 


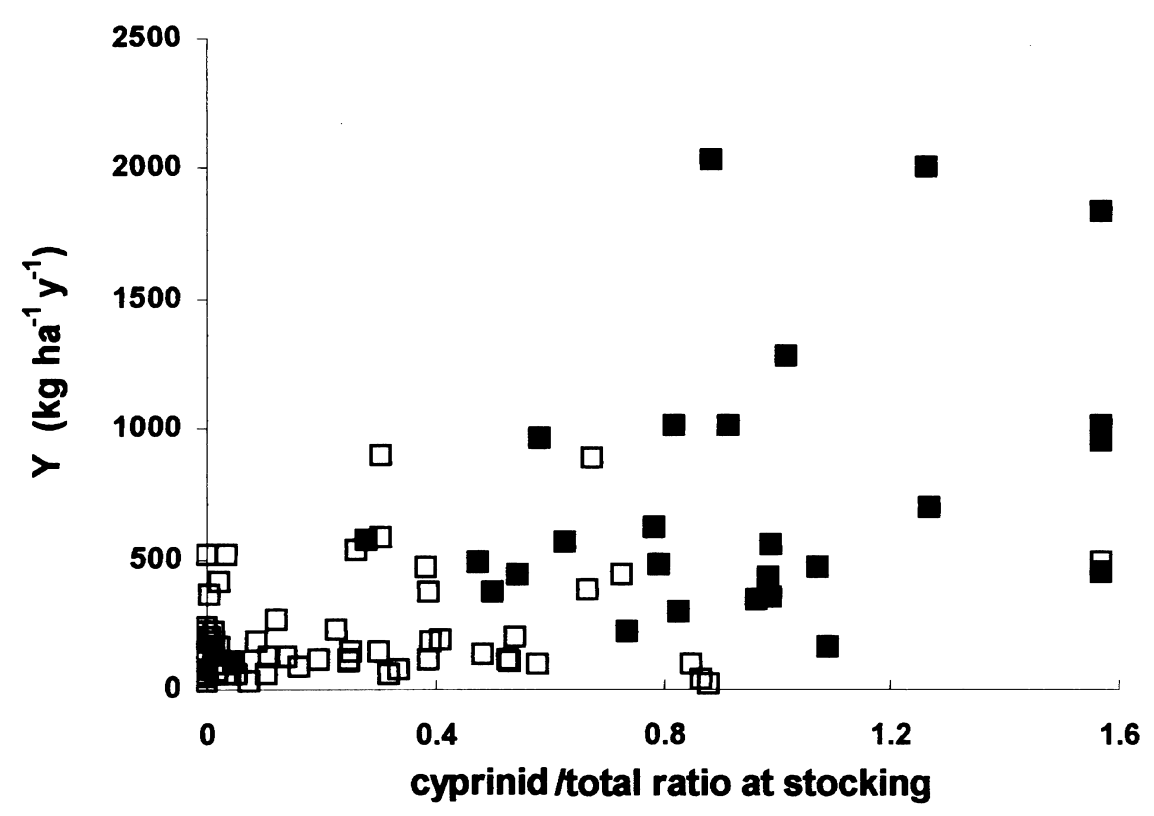

Figure 6 Relationship between total yield ( $\left.\mathrm{Y}, \mathrm{kg} \mathrm{ha}^{-1} \mathrm{year}^{-1}\right)$ and cyprinid to total fish biomass ratio at stocking (arcsine transformed) for 86 Cuban reservoirs: $(\square)$ extensively used reservoirs; and ( $\square$ ) semi-intensively used reservoirs.

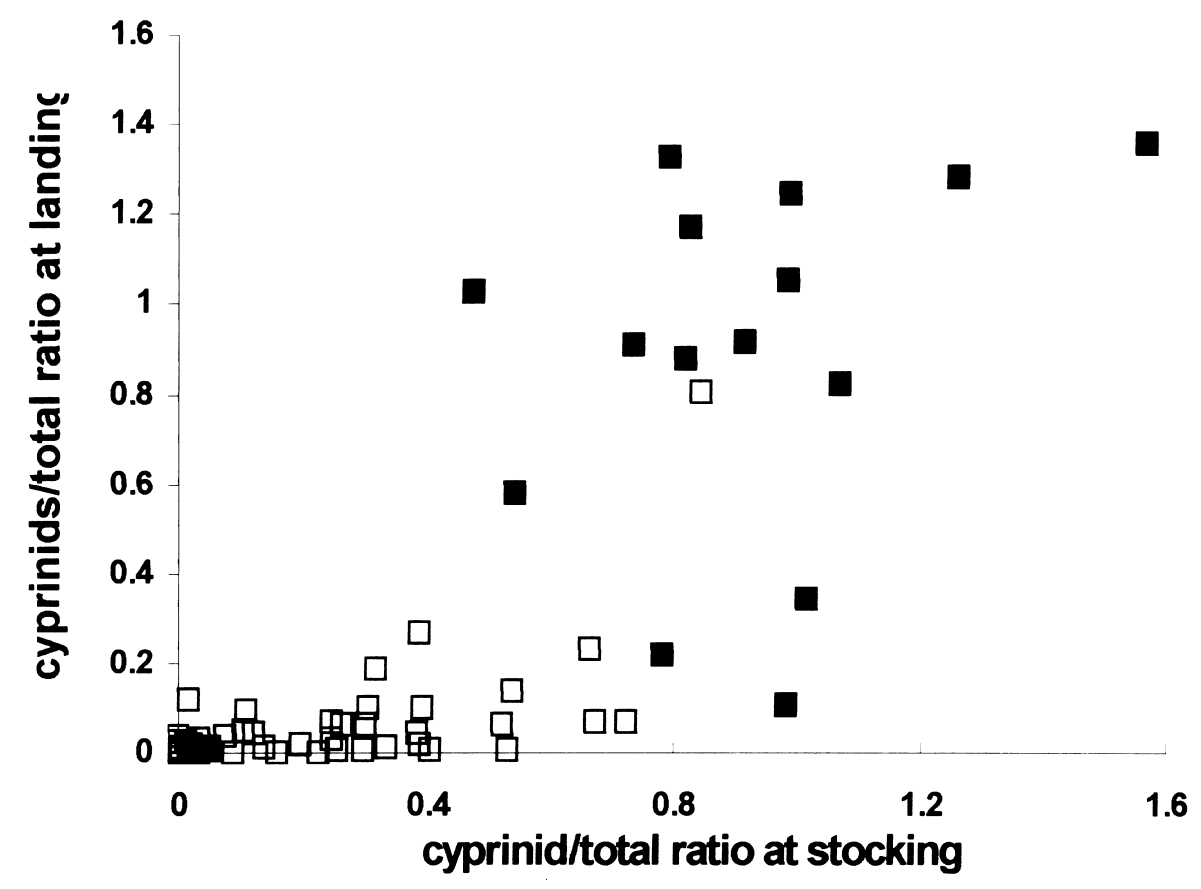

Figure 7 Relationship between cyprinid to total fish biomass ratio at landing and at stocking (both arc-sine transformed) for 86 Cuban reservoirs: ( $\square$ ) extensively used reservoirs; and ( $\square$ ) semi-intensively used reservoirs.

(C) 1999 Blackwell Science Ltd, Fisheries Management and Ecology 1999, 5, 241-254 


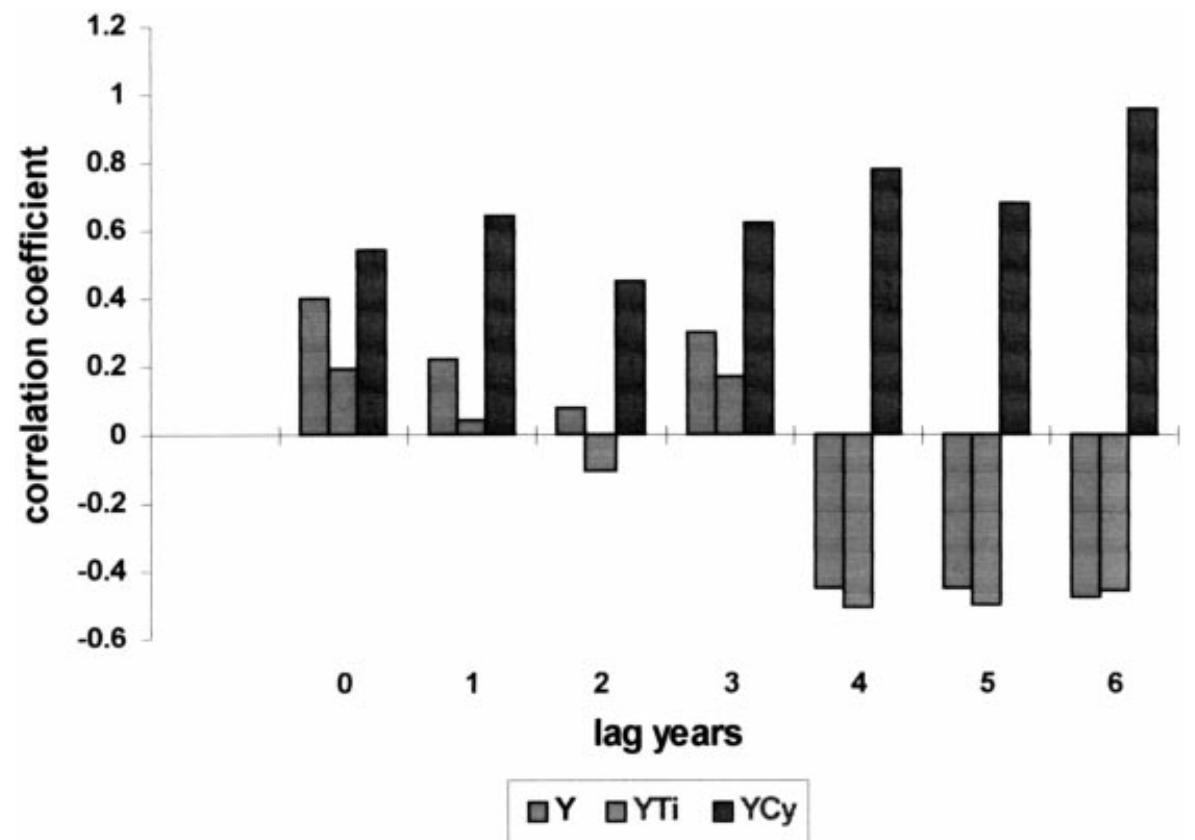

Figure 8 Lag-correlation analysis between yield and stocking density for 49 Cuban reservoirs: (Y) results for total fish; (YTi) results for tilapia; and (YCy) results for Chinese carp. The time series is for the period from 1973 to 1993.

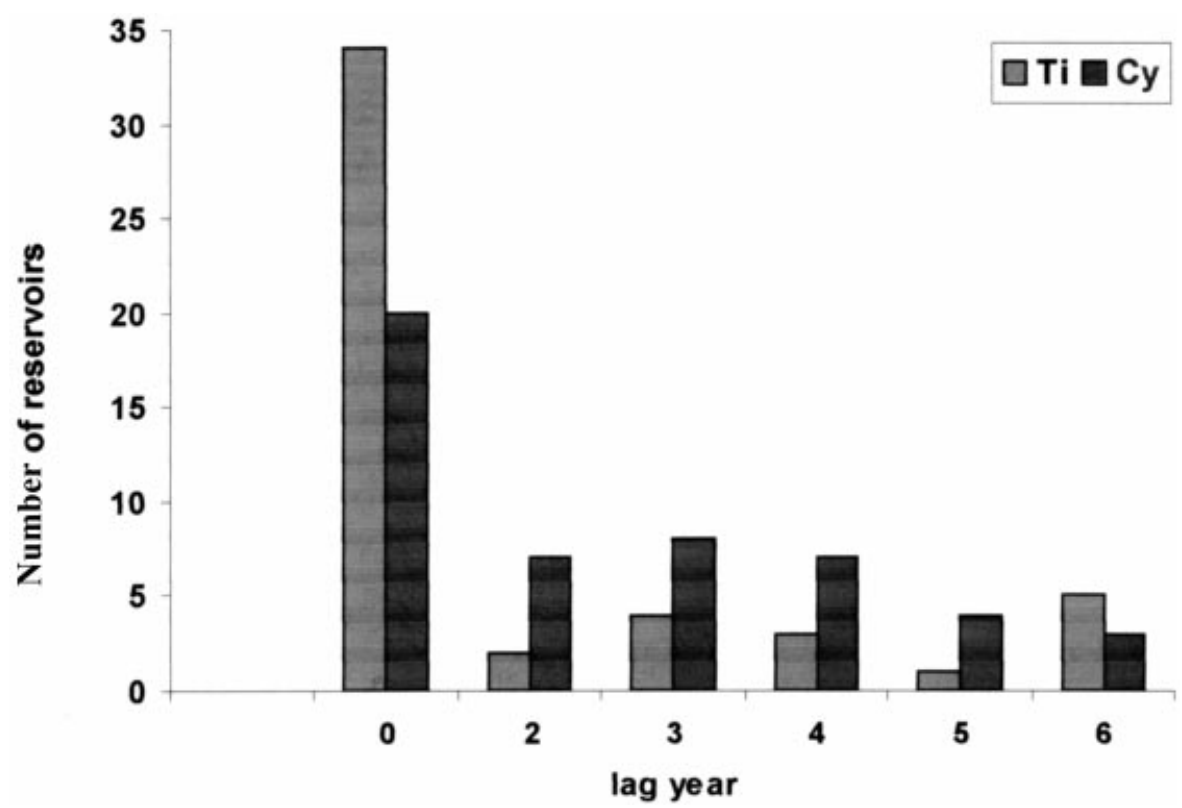

Figure 9 Number of Cuban reservoirs with significant lag-correlations for the period from 1973 to 1993. Forty-nine reservoirs were analysed: (Ti) results for tilapia; and (Cy) results for Chinese carp. 
and 1-year lags may be related to high cyprinid stocking for the years 1992 and 1993 (Fig. 2). There were no significant lag-correlations for tilapia and for total fish, although the positive relationship from lags 0 to 2 may be related to high stockings for the period 1991-1993 (Fig. 1).

An extensive time-series analysis of stockings for 49 extensively used Cuban reservoirs during the 1973-1993 period was conducted by Fonticiella et al. (1995) (Fig. 8). Six of these reservoirs were moved to semi-intensive use in the last few years of the period analysed. For more than half $(n=29)$ of the reservoirs, the cyprinid stocking rate was significantly $(P<0.05)$ related to cyprinid yield with time lags of between 2 and 6 years. For tilapia, the stocking rate was significantly related $(P<0.05)$ to yield for one-third of the reservoirs $(n=15)$. Most of the reservoirs showed significant but spurious correlations for synchronic time-series analyses $($ year lag $=0)$.

It cannot be determined to what extent the more productive reservoirs were heavily stocked. However, the high number of reservoirs with significant correlations for lag 0 (Fig. 9) may indicate a fishery management bias; the most used reservoirs were heavily stocked with tilapia and cyprinids, and intensively fished in the same year.

The stocking effectiveness for Cuban reservoirs may be compared with a previously obtained relationship between residuals of the SDW $-\mathrm{Y}$ regression and stocking density for Latin

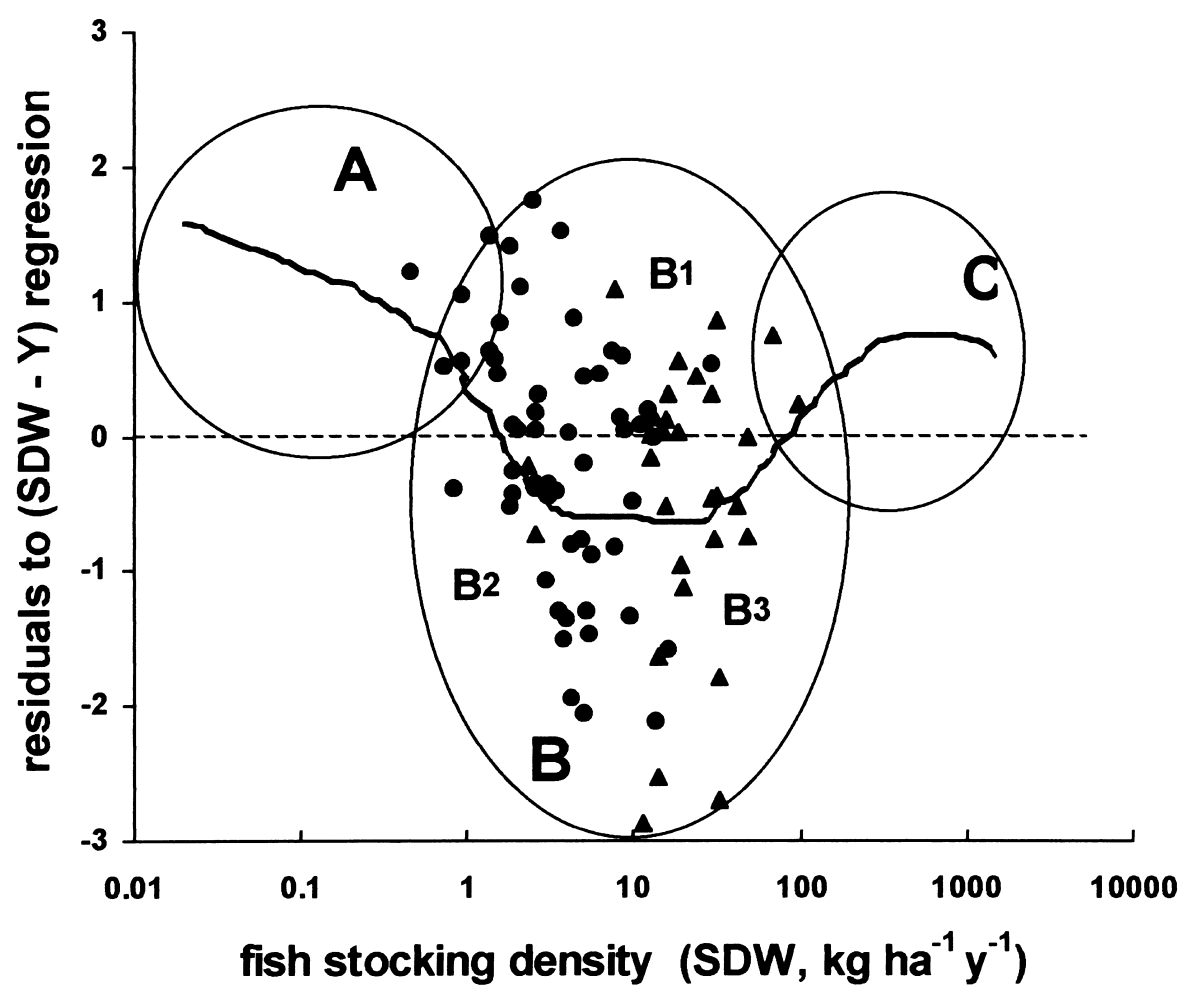

Figure 10 General residual distribution patterns for Latin American water bodies (modified from Quiros 1997): (@), extensively used Cuban reservoirs; and $(\boldsymbol{\Delta})$, semi-intensively used Cuban reservoirs. 
American water bodies (Quiros 1998. Only a few large and medium-sized extensively used Cuban reservoirs are included in the group which has a relatively low fish yield and low stocking density suited to the presence of self-sustained fish populations (Fig. 10, A). However, most of the Cuban reservoirs are in the group that includes medium-sized, small and very small reservoirs used for extensive or semi-extensive fish production, and have been stocked at medium to large stocking densities (Fig. 10, B). Three chief subgroups were characterized for this subset. The first includes medium-sized and small reservoirs that deviate positively from the general log-log regression model which relates fish yield to fish stocking density (Fig. 10, B1). For this group, stocking linked to morphoedaphic factors, external inputs (e.g. fertilizers) and/or to the presence of self-sustained fish populations may be beneficial. More than one-third of the Cuban reservoirs studied belong to this subgroup. However, almost half of the mediumsized and small reservoirs deviated negatively from the general stocking-yield relationship, including medium-sized reservoirs used for extensive culture-based fisheries (Fig. 10, B2), and small and very small reservoirs used for semi-intensive culture (Fig. 10, B3). For the former subset, self-sustained populations are usually present or stocking is not adapted to carrying capacity. For the latter, stocking is usually not adapted to fertilization levels, and therefore, fish yields are lower than predicted. More than half of small and very small reservoirs are included in this subset (Fig. 10, B3).

\section{Discussion}

The weak relationship between total fish yield and stocking rate for reservoirs under extensive exploitation was expected. Most of the extensively used reservoirs have self-sustaining fish populations, more than half of which have no recruitment problems. Moreover, the potential natural productivity for stocked reservoirs was not considered in the Cuban stocking programme. It is to be expected that morphoedaphic factors (Ryder 1965), total organic load and hydrology (water residence time) will have a great influence on tropical reservoir extensive fish production (A. Mari \& R. Quiros, unpublished data).

Cuban fishery managers have developed reservoir fisheries based on stocking. The tilapia fisheries are well-managed and have not required further stocking since the initial introduction of the fish. However, since 1990, the stocking of tilapia has not been adjusted to account for natural recruitment of existing stocks. In contrast, cyprinid fisheries have been based on continuous stocking.

Other reservoir data sets have been studied world-wide for the relationship between fish yield and stocking rate (De Silva, Lin \& Tang 1992; Quiros 1994, 1998). Heavy stocking usually results in higher fish yields, but stocking is not the only condition necessary to achieve a successful outcome. Other conditions, such as the presence of self-sustained and/or nonreproducing fish populations, exploitation of stocked fish, external inputs (fertilizers and/or food) adapted to stocking rates, and stocking rates adapted to carrying capacity and/or external inputs, must also be considered (Quiros 1998).

In none of the cases examined was there an inverse relationship between the yield from stocking and the reservoir area. Therefore, it must be concluded that the practice of using large reservoirs for intensive production and small ones for semi-intensive production depends more 
on the high costs of enhancement than on any biological evidence of lower success in the stocking of large systems. Moreover, the yield from stocking was usually higher for larger reservoirs because of the presence of self-sustained fish populations.

For tropical Latin America as a whole (Quiros 1998), total fish yield was positively correlated with stocking density, grade of intensification and mean weight of fish at stocking. Moreover, fish yield was inversely related to surface area. These patterns were not displayed, at a small scale of data variation, for Cuban reservoirs.

The relationship between fish yield and stocking density is a good indicator for stocking success when the objective is to maximize biomass (De Silva et al. 1992; Quiros 1998). The relationship between stocking density and fish yield may also be a good indicator for stocking success in Cuban reservoirs. Both tilapia and Chinese carp have been successful introduced to Cuban fresh waters. However, the results from the tilapia stocking programme in Cuban reservoirs have shown that stocking is not a good management measure when insufficient recruitment to the fishable population is evident. On the other hand, the results from the Chinese carp stocking programme show the need for the continuous addition of young fish to

develop fishable stocks; stocking must be suited to: the natural carrying capacity of a reservoir (Mari \& Quiros, unpublished data), diffuse external organic matter inputs, and external inputs of fertilizers and food (Song 1980; Lu 1992; Quiros 1998). Some other plausible and alternative explanations related to the fishing effort and applied to cyprinid stocks in extensively used reservoirs are discussed in Fonticiella et al. (1995).

Stocking is not a magic management measure to increase fish yield. For Cuban reservoirs, current stocking practices should change from indiscriminate stocking attempting to exceed natural or actual capacity to decisions based on the productive capacities of water bodies, sound fisheries enhancement measures and fish community compatibility. Stocking should be suited to the presence of self-sustained tilapia populations and should be assessed for each reservoir.

An important result from the analysis of the Cuban reservoir tilapia fisheries was that it was cost effective for the extensively used, relatively low stocked fisheries for the period from the 1970s into the 1980s. On the other hand, economic analyses were negative for overstocked tilapia cyprinid fisheries (Fonticiella et al. 1995). However, social benefits may cancel economic costs for the Cuban reservoir fisheries (Fonticiella et al. 1995).

\section{Acknowledgements}

R. Quiros acknowledges research support from the Consejo Nacional de Investigaciones Cientificas y Tecnologicas (CONICET). We are grateful to Ian Cowx and Tomi Petr for insightful comments on and improvements to an earlier version of this paper. We would also like to thank two anonymous reviewers for constructive and helpful reviews of this paper.

\section{References}

Cowx I.G. (1999) An appraisal of stocking strategies in the light of developing country constraints. Fisheries Management and Ecology 6, 21-34. 
Davis J.C. (1986) Statistics and Data Analysis in Geology, 2nd edn. New York, NYA: John Wiley \& Sons Inc., $646 \mathrm{pp}$.

De Silva S.S., Lin Y. \& Tang G. (1992) Possible yield-predictive models based on morphometric characteristics and stocking rates for three groups of Chinese reservoirs. Fisheries Research 13, 369380.

Draper N.R. \& Smith H. (1981) Applied Regression Analysis. New York, NY: John Wiley \& Sons Inc., $709 \mathrm{pp}$.

Fonticiella D.W., Arboleya Z. \& Diaz Perez G. (1995) La repoblacion como forma de manejo de pesquerias en la acuicultura de Cuba. COPESCAL Documento Ocasional, No. 10, 45 pp.

Hintze J.L. (1988) Number Cruncher Statistical System (NCSS), Version 5.1. Graphics. Dr Jerry L. Hintze, Kaysville, UT, 69 pp.

Lu X. (1992) Fishery management approaches in small reservoirs in China. FAO Fisheries Circular, No. $854,69 \mathrm{pp}$.

Mari A. (1992) Pesquerias derivadas de la acuicultura en aguas interiores de Cuba. In: Manejo y Explotacion Acuicola de Embalses de Agua Dulce en America Latina Proyecto GCP/RLA/075/ITA. Documento de Campo No. 1, pp. 72-105.

Quiros R. (1994) Intensificación de la pesca en los pequeños cuerpos de agua en America Latina y el Caribe. COPESCAL Documento Ocasional, No. 8, Rome, 41 pp.

Quiros R. (1998) Reservoir stocking in Latin America, an evaluation. In: T. Petr (ed.) Inland fishery enhancements. FAO Technical Paper 374, 91-118.

Ryder R.A. (1965) A method for estimating the potential fish production of north-temperate lakes. Transactions of the American Fisheries Society 94, 214-218.

Song Z. (1980) Manual of small-scale reservoir fish culture. FAO Fisheries Circular, No. 727, 18 pp.

Weisberg S. (1980) Applied Linear Regression. New York: John Wiley \& Sons Inc., 283 pp.

Welcomme R.L. (1998) Evaluation of stocking and introductions as management tools. In: I. G Cowx (ed.) Stocking and Introduction of Fish. Oxford: Fishing News Books, Blackwell Science Ltd, pp. 397-413.

Welcomme R.L. \& Bartley D.M. (1997) An evaluation of present techniques for the enhancement of fisheries. Fisheries Management and Ecology 5, 351-382. 